\title{
Interferometric radar observations of Glaciares Europa and Penguin, Hielo Patagónico Sur, Ghile
}

\author{
Richard R. Forster, ${ }^{1 *}$ Eric Rignot, ${ }^{2}$ Bryan L. Isacks, ${ }^{1}$ Kenneth C. JezeK ${ }^{3}$ \\ ${ }^{1}$ Department of Geological Sciences, Cornell University, Ithaca, New York 14853, U.S.A. \\ ${ }^{2}$ Jet Propulsion Laboratory, California Institute of Technology, Pasadena, California 91109, U.S.A. \\ ${ }^{3}$ Byrd Polar Research Center, The Ohio State Lniversity, Columbus, Ohio 43210, U.S.A.
}

\begin{abstract}
Repeat-pass L-band interferometric synthetic aperture radar (InSAR) data for part of Hielo Patagónico Sur, Chile, were collected by the space-shuttle-based Spaceborne Imaging Radar G (SIR-C) over a 4 day span in October 1994. Three co-registered complex SAR images are used to generate phase-coherence maps, a digital clevation model (DEM) and an ice-velocity map. The phase-coherence maps indicate low coherence in the $5-15 \mathrm{~km}$ approaching the termini due to large displacements, ice deformation and melting. However, the coherence is high over nearly all of the remaining imaged icefield. Ice-velocity precision is greater than $2 \mathrm{~cm} \mathrm{~d}^{-1}$, while the DEM is good to about $25 \mathrm{~m}$. A flow divide between two of the glaciers is mapped by locating a narrow band of ncar-zcro icc velocity. Horizontal ice-surface velocity profiles calculated along flowlines show there is a high degree of spatial variability reaching a peak value of $5.5 \mathrm{~m} \mathrm{~d}^{-1}$ located $3.5 \mathrm{~km}$ from the terminus of Glaciar Europa. Longitudinal strain rates along the center lines calculated from these velocities at the locations of the initiation of crevassing are used to compute the tensile strength of ice $(169-224 \mathrm{kPa})$.
\end{abstract}

\section{INTRODUCTION}

The Patagonian icefields, consisting of Hielo Patagónico Sur (HPS; Fig. 1) and the smaller Hielo Patagónico Norte (HPN), are the only large, temperate, mid-latitude ice masses in the Southern Hemisphere, and thus are key areas for the study of glacial response to climatc change. HPS has high precipitation rates estimated at over $7000 \mathrm{~mm} \mathrm{a}^{-1}$ w.e. (Escobar and others, 1992) and large ablation rates due to the relatively warm air temperatures (Aniya and others, 1992). The combination produces a glacial system with a large but unquantified ice flux that should respond quickly to climatic variations. Despite HPS's significance, there is little glaciological information availablc, mainly because of perennially inhospitable weather (Warren and Sugden, 1993) which has discouraged field investigations and limited classic methods of remote-sensing research. Glacier velocities have been measured on only 6 of the 48 outlet glaciers (C. R. Warren unpublished data, 1993; Nishida and others, 1995; Skvarca and others, 1995; Warren and others, 1995; Rivera and others, 1997; Skvarca and Naruse, 1997; Skvarca and others, in press), and no complete mass-balance studies havc been done on any of the glaciers (Warren and Sugden, 1993).

Of particular interest is the contribution of the Patagonian icefields to present and future sea-level change. In order to estimate this quantity, some fundamental glaciological data must first be obtained. Ice-flux measurcment requires knowledge of the velocity field. Glacier massbalance calculation necessitates the location of flow divides and topographic information. Estimation of the past and

\footnotetext{
* Present address: Department of Geography, University of Utah, Salt Lake City, Utah 84112-9155, U.S.A.
}

future changes in mass balance requires models that ideally incorporate glacier dynamic quantities such as the spatial distribution of velocity and strain rates. To understand the calving process and the formation of crevasses, estimates of the ice strength are essential.

Interferometric synthetic aperture radar (InSAR) techniques represent the most promising method of acquiring glaciological data over such vast and remote areas. The glaciological data are derived from the InSAR ice-motion and digital elevation maps with a high spatial resolution $(<30 \mathrm{~m}$ ). InSAR data for HPS and HPN (Rignot and others, 1996a, b) were collected from NASA's space-shuttlebased Spaceborne Imaging Radar C (SIR-C) in October 1994. A $37 \mathrm{~km}$ wide transect of the southern HPS (Fig. l) was imaged on 7,9 and 10 October 1994 nearly 48 and $24 \mathrm{~h}$ apart, respectively, with a look angle of $34^{\circ}$ from the vertical. SIR-G interferometric data were acquired with vertical transmit and vertical receive (VV) polarization at L-band $(\lambda=24.23 \mathrm{~cm})$ and $\mathrm{C}$-band $(5.67 \mathrm{~cm})$. We use the longerwavelength $\mathrm{L}$-band data because they have been found to be superior to the shorter-wavelength C-band data for the temperate, fast-moving Patagonian glaciers (Rignot and others, 1996a). The accurate repeat of the space-shuttle orbits on the 3 days produced short baselines (the distance separating the antenna positions between the orbits) which are ideal for detecting surface displacements (Table 1). Although short-baseline interferometers do not produce highly accurate topographic maps, they are adequate for removing the topographic influence from the displacement signal.

The short tcmporal baseline and the long wavelength of the SIR-C InSAR data provide a unique set of conditions for the study of temperate glaciers. While Earth Resources Satellite (ERS) interferometry data with short temporal base- 

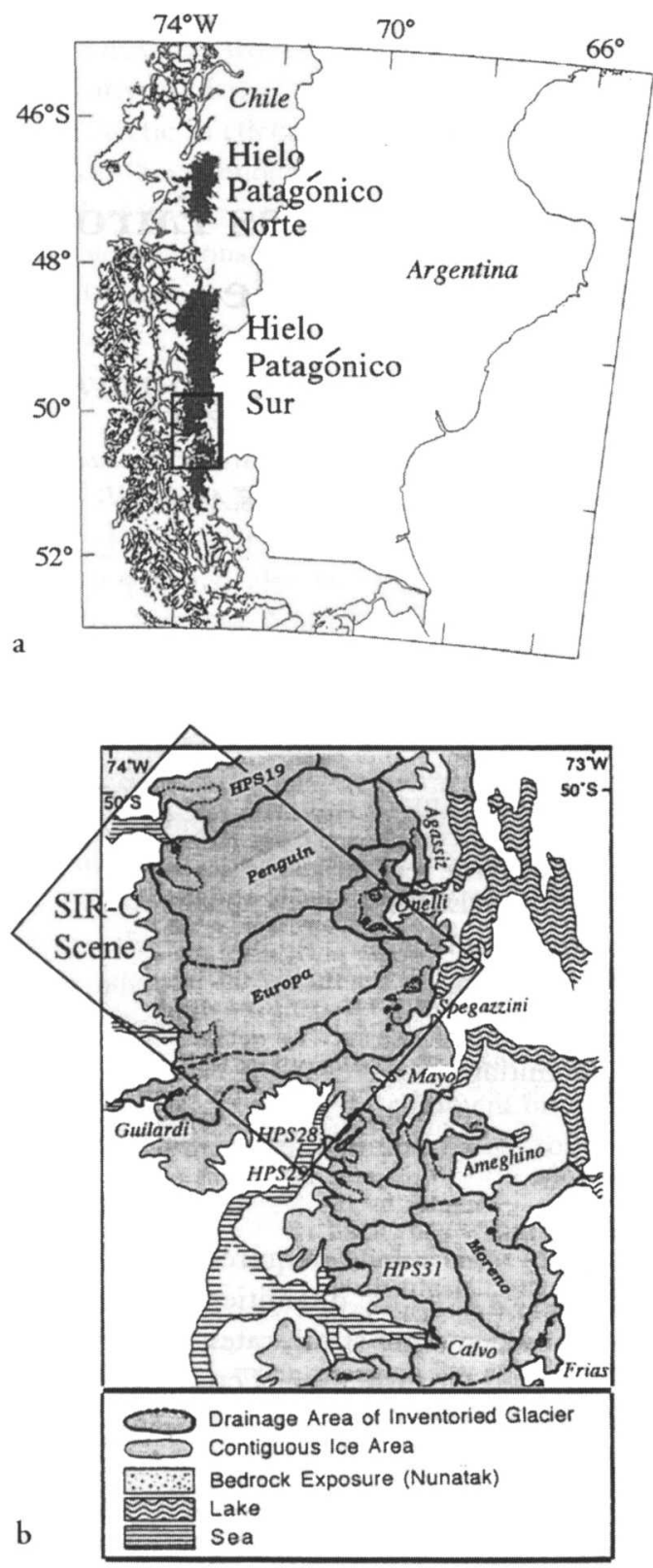

Fig. 1. (a) Location of HPNand HPS. (b) The Penguin and Europa glacier areas with localion of SIR-C swath (modified after Aniy a and others, 1996).

lines (1- 6 day repeat orbits) have been used successfully on the polar ice sheets of Greenland (Joughin and others, 1995; Rignot and others, 1995; Joughin and others, 1996a, b, c; Kwok and Fahnestock, 1996; Rignot, 1996; Rignot and

Table 1. Interferometric SAR temporal and spatial baselines estimated from control points. The baseline components are perpendicular $\left(B_{\mathrm{n}}\right)$ and parallel $\left(B_{\mathrm{p}}\right)$ relative to the illumination direction

\begin{tabular}{lccccc}
\hline \multicolumn{2}{c}{$\begin{array}{c}\text { SAR acquisition } \\
\text { (1994 GMT) }\end{array}$ Single-difference baseline } & Effective double-difference \\
Date & Time & $B_{\mathrm{n}}$ & $B_{\mathrm{p}}$ & $B_{\mathrm{n}}$ & $B_{\mathrm{p}}$ \\
& $\mathrm{h}$ & $\mathrm{m}$ & $\mathrm{m}$ & $\mathrm{m}$ & $\mathrm{m}$ \\
\hline 7 October & 2147 & & & & \\
9 October & 2101 & -74 & 13 & & 16 \\
10 October & 2038 & 28 & 3 & -46 & \\
\hline
\end{tabular}

others, 1997) and Antarctica (Goldstein and others, 1993; Kwok and others, 1996; MacAyeal and Rignot, 1996), the C-band wavelength has provided only limited success on temperate glaciers (Fatland and Lingle, 1996; Vachon and others, 1996). L-band SAR data arc available from the previously orbitingJERS-1, but the 44 day temporal baseline is generally too long for the fast-changing temperate glaciers.

This paper begins with a description of the imaged area, goes on to outline the steps used in the generation of the interferometric products - phase-coherence maps, a digital elevation model (DEM) and an ice-velocity map in the radar line of sight - and examines the uncertaintics in these products. The last section presents a detailed analysis of the ice velocities.

\section{PENGUIN AND EUROPA GLACIER AREA}

The part of the swath that was analyzed includes the western side of HPS which contains the terminus and most of the drainage areas of the Penguin and Europa outlet glaciers and the terminus of an unnamed glacier (referred to as HPS-19 by Aniya and others, 1996). All three outlets are tidewater glaciers. The L-band amplitude image acquired on 7 October 1994 at $1647 \mathrm{~h}$ local time is shown in Figure 2. The radar bright areas at and above the tidewater termini of the glaciers are probably the result of strong multiple reflections from a heavily dissected crevasse region typical of other HPS calving glaciers (personal visit, 1995). The darker areas up-glacier represent smoother parts of the interior of the icefield. Careful examination reveals flowlines in the upper Penguin and Europa glaciers and bright areas in the middle part of Glaciar Europa which are caused by crevassing. The nunataks are imaged as the bright, roughly textured features protruding through the icefield.

The catchment area of these three glaciers (along with the other 45 HPS outlet glaciers) have been estimated from Landsat Thematic Mapper (TM) images at 530,409 and $177 \mathrm{~km}^{2}$ for the Penguin, Europa and HPS-19 glaciers, respectively (Aniya and others, 1996). The ice divides, estimated from flowlines on TM scenes and aerial photographs, arc poorly constrained between Glaciares Penguin and Europa (see Fig. 1b).

\section{GENERATION OF INTERFEROMETRIC PRODUCTS}

The theoretical background of InSAR has been discussed in detail by Zebker and Goldstein (1986), with the specific application to glacier studies by Goldstein and others (1993), Joughin and others (1996b) and Kwok and Fahnestock (1996). The interferometric techniques used in this paper closcly follow those of Rignot and others (1996a).

The main objective of this work is to isolate the surface displacement contribution and construct a map of one component of the ice velocity (in the radar-look direction) in order to estimate the ice-surface velocity field. This is achicved by first generating two interferograms using the three complex SAR images (Zebker and Goldstein, 1986). During the generation of the interfcrograms the slant-range pixels (azimuth $5.2 \mathrm{~m}$, range $3.3 \mathrm{~m}$ ) are re-sampled with a $3 \times 3$ averaging window to reduce noise at the expense of decreased spatial resolution. A 2 day interferogram is generatcd from the complex data acquired on 7 and 9 October (Table 1). A I day interferogram is produced from 9 and 10 October complex data. The phase of the 1 day interferogram 


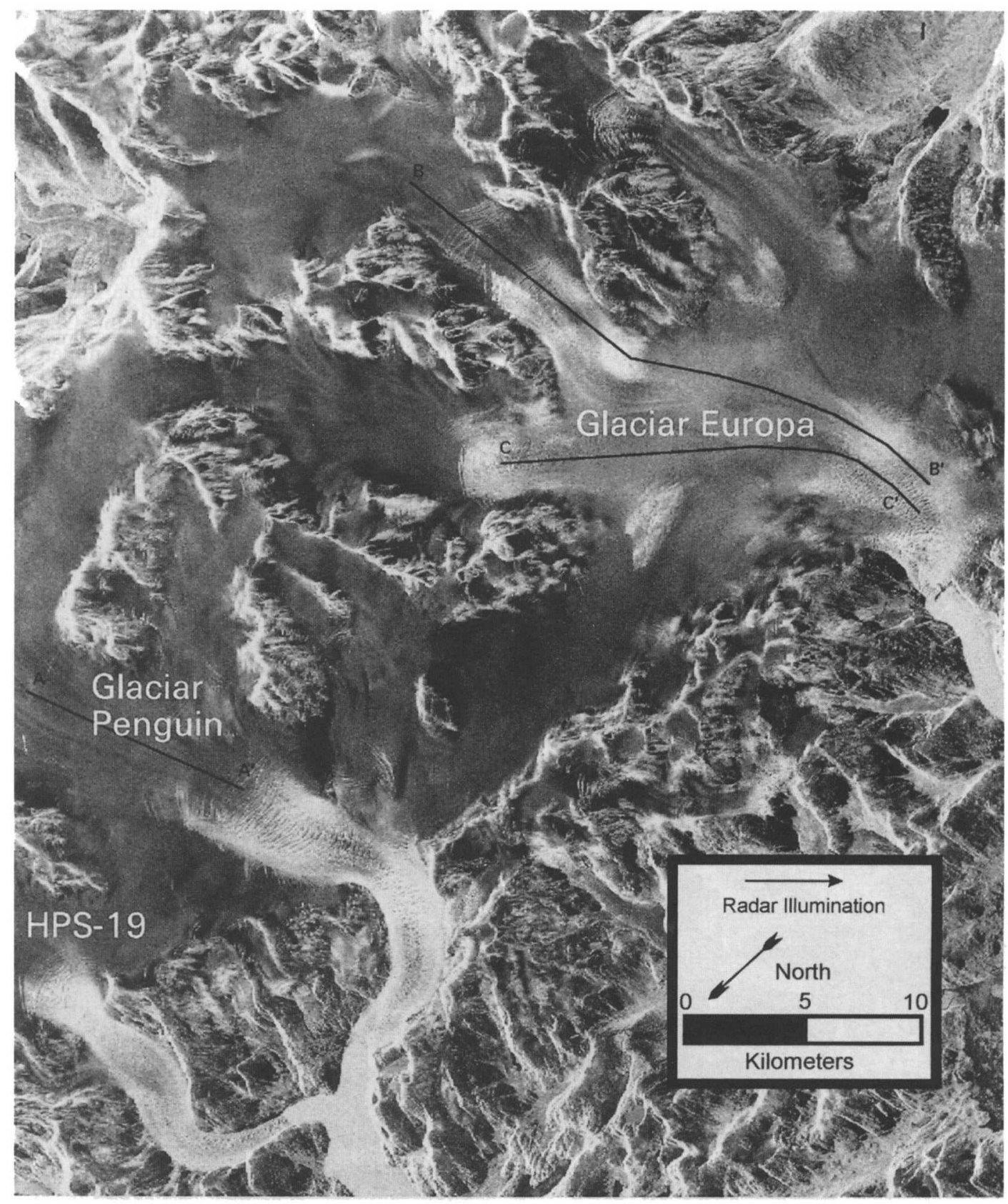

Fig. 2. L-band amplitude image of part of HPS containing Glaciar Europa, Glaciar Penguin and HPS-19, acquired on 7 October 1994. The image is $37 \mathrm{~km} \times 47 \mathrm{~km}$ illuminated from the left, with north toward the bottom left. The black lines are the locations of the velocity profiles showen in Figures $7-9$.

is scaled (by 2.05) to compensate for the differences in temporal basclines. Assuming constant ice velocity, this equalizes the phase due to displacement for the 1 and 2 day interferograms. The 2 day and scaled 1 day interferograms are then subtracted, forming a "double-difference" interferogram which contains no phase contribution from displacements occurring during the acquisition period (Kwok and Fahnestock, 1996). When the double-difference technique is applied to glacier surfaces, the assumption is made that the ice velocity has been constant throughout the period. This is a reasonable assumption for the large outlet glaciers samplcd about $24 \mathrm{~h}$ apart, with the possible exception of the terminal areas which can have large sub-daily velocity variations (Naruse and others, 1995).

The double-difference interferogram is used to generate a DEM. First, the phase contribution resulting from the different satellite positions (baseline) is removed using groundcontrol points (personal communication from A. Rivera, 1997) and space-shuttle ephemerides data, a process referred to as "flattening" the interferogram. The modulo $2 \pi$ phase is then integrated (unwrapped) (Goldstein and others, 1988) and converted to a DEM using knowledge of the satellite position.

The 1day interferogram is also flattened and unwrapped, leaving phase contributions from topography and displacement. The topographic contribution is removed using the InSAR DEM. Finally, only the displacement contributes to the phase of the 1 day flattened-unwrapped interferogram, which is then converted to a map of ice velocity $\left(v_{\mathrm{r}}\right)$ in the direction of the radar illumination:

$$
v_{\mathrm{r}}=\phi_{\mathrm{d}} \frac{\lambda}{4 \pi T},
$$

where $\lambda$ is the wavelength $(24.23 \mathrm{~cm}), \phi_{d}$ is the phase due to displacement and $T$ is the time between acquisitions. 


\section{INTERFEROMETRIC PRODUCTS}

\section{Coherence maps}

An image of the magnitude of the spatially averaged crosscorrelation function used to generate the interferograms indicates the level of phase coherence throughout the scenes and is referred to as a coherence map (Zebker and Villasenor, 1992). These maps provide a spatial indication of the quality of the interferometric data, with areas of high phase coherence corresponding to bright areas, while areas of low coherence are imaged as dark areas (Fig. 3a and b). The phasc-coherence maps of both the 1 and 2 day interferograms indicate there are significant spatial variations in the near-surface properties of the icefield. Differences betwcen the two maps are a result of changes in these properties during the 4 days that span the acquisition period and are also due to the difference in the amount of ice motion observed by the 1 and 2 day intcrferograms.

The coherence of the icefield from the 2 day interferogram (Fig. 3a) is generally high $(>0.7)$, while the nunataks and rock surfaces at the margin arc low $(<0.3)$. The coherence is very low $(<0.1)$ at the termini of all three outlet glaciers, and this low-coherence area extends significant distances up-glacier (HPS-19; $10 \mathrm{~km}$; Glaciar Penguin: $12 \mathrm{~km}$; Glaciar Europa: $3.5 \mathrm{~km}$ ). The complete loss of coherence in these areas probably results from the large displacements and the rotation of the individual seracs forming the
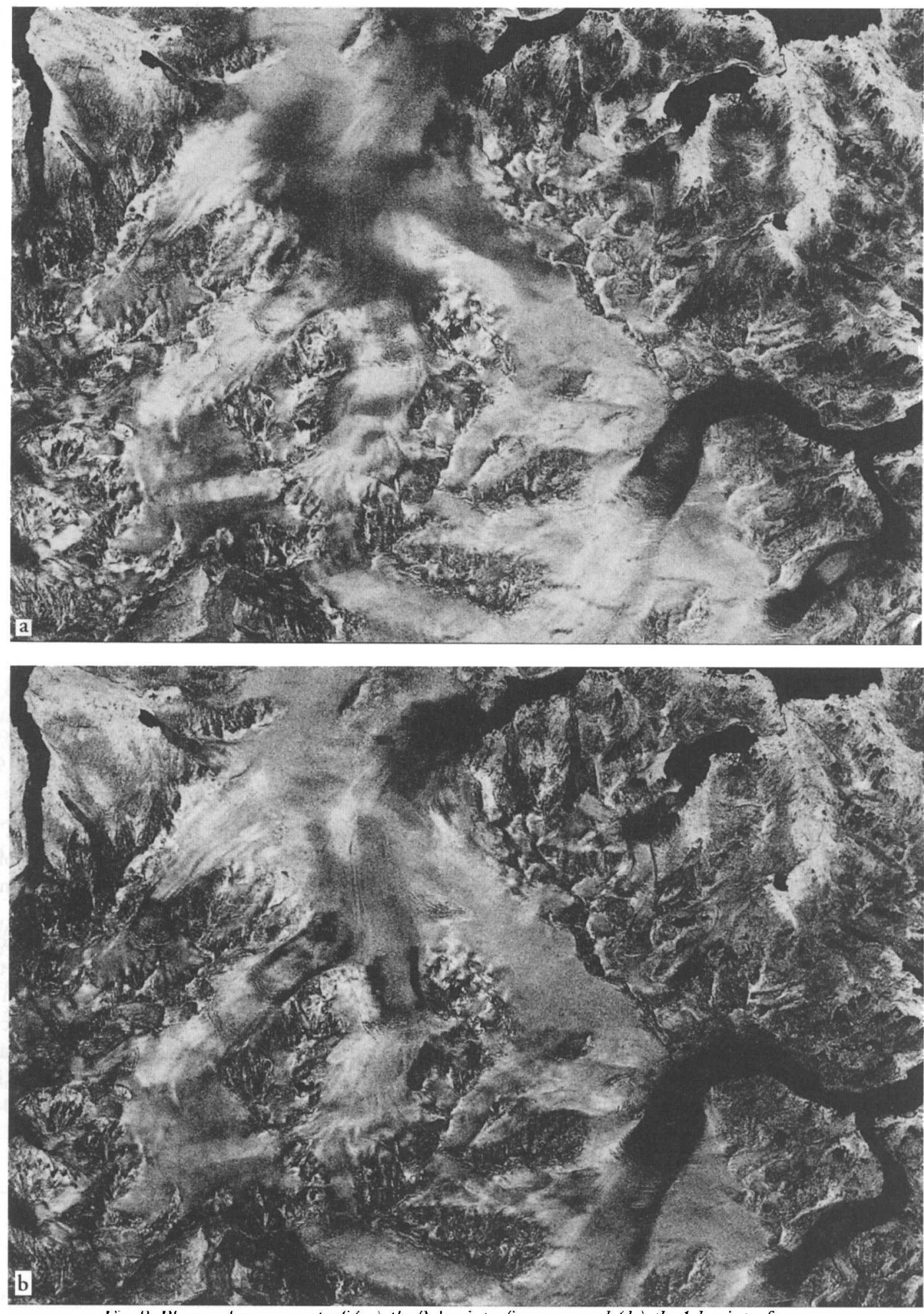

Fig. 3. Phase coherence map of $(a)$ the 2 day interferogram and $(b)$ the 1 day interferogram. 
fractured surface (Rignot and others, 1996a). 'The abrupt loss of coherence at the margins of the two upper tributaries of Glaciar Europa can be explained by a combination of the rotation of the ice within the shear margins and large velocity gradients. This effect is seen to a lesser degree within the right shear margin of Glaciar Penguin.

The loss of L-band phase coherence has been observed approaching the termini of all Patagonian glaciers imaged during the SIR-C mission (Glaciar Moreno (Rott and others, 1998; Michel and Rignot, 1999) and four HPN glacicrs (Rignot and others, 1996b)). The intense deformation and potential for melting typical of the lower parts of Patagonian glaciers makes classical InSAR phase measurements ineffective near the terminus. However, alternative approaches that usc only the two-dimensional cross-correlation of the amplitude images can extend the displacement measurements to the terminus (Rignot and others, 1996a; Rott and others, 1998; Michel and Rignot, 1999). While these methods are less sensitive to temporal decorrelation and provide a two-dimensional velocity vector, their accuracy is degraded by more than an order of magnitude (Rott and others, 1998). Since this work focuses on areas away from the termini and utilizes the high accuracy required for calculating ice stress and locating flow divides, only the phase InSAR technique is used.

There are substantial differences between the 2 and 1 day coherence maps which, we believe, are related to the difference in time spanned by the interferograms and to the effects of changing surface properties. The shorter time interval of the l day interferogram translates into maintaining coherence at faster ice velocities, and a greater tolerance of daily rotation of ice blocks. The net effect of this is to extend the area of high coherence further down the glaciers and to provide higher coherence within the shear margins (Fig. $3 \mathrm{~b}$ ). The large area of low coherence on the lower part of Glaciar Europa cannot be explained by a time-interval change, and the relationship is the opposite of what would be expected for temporal decorrelation, In this area the 2 day coherence is higher than the 1 day coherence. The sequence of amplitude images (not shown) indicates that the radar return in this area is relatively unchanged between the days forming the 2 day interferogram ( 7 and 9 October) but increases dramatically on the last acquisition (10 October) which is used in the 1 day interferogram.

A large change in the radar return can be caused by a change in the dielectric properties of the glacier, which would alter the phase response and hence cause a low phase coherence. Melting or freezing of a snowpack can cause large changes in radar return (Mätzler, 1987) and is the suspected cause of the low coherence. Vachon and others (1996) found very low coherence $(<0.2)$ on all pairs of their ERS tandem dataset of a Canadian temperate glacier when the temperatures were above freezing during the acquisitions. Something similar to the HPS data was observed with an ERS-1 6 day coherence map having an area of higher coherence than the sequential 3 day coherence map (Zebker and others, 1994). From temperature records they concluded the freezing of the soil and vegetation were responsible for the area of low coherence and that freezing or thawing of surfaces, in general, would cause low coherence.

While there are no temperature records or ground observations of Glaciar Europa during this time, an automatic weather station (AWS) was in place on Glaciar Moreno (Fig. 1b) approximately $50 \mathrm{~km}$ to the southeast (Takeuchi and others, 1996). The daily mean temperatures at the Moreno station during the 4 days of the SIR-C acquisitions indicate a warming trend (Table 2). The temperatures are extrapolated to the elevation range of the low-coherence area on Glaciar Europa using a lapse rate determined on Glaciar Moreno (Takeuchi and others, 1996). There may be errors in values and the timing of the extrapolated temperatures since Glaciar Moreno is on the eastern side of the continental divide. The temperatures suggest that near-freezing conditions may have prevailed between 7 and 9 October, while there could have been more melting on 10 October 1994. Extended melting on the surface of the glacier between the acquisitions of the lday coherence map would account for the low-coherence area.

Table 2. Calculated temperatures at $1200 \mathrm{~m}$ from AWS data on Glaciar Moreno, Argentina (Takeuchi and others, 1996)

\begin{tabular}{cc}
\hline Date & $\begin{array}{c}\text { Air temperalure } \\
{ }^{\circ} \mathrm{C}\end{array}$ \\
& \\
\hline 7 October 1994 & -2.2 \\
8 October 1994 & -3.4 \\
9 October 1994 & -0.2 \\
10 October 1994 & 2.0 \\
\hline
\end{tabular}

\section{Icefield surface topography}

The DEM generated from the double-difference interferogram is sufficient to remove the topographic phase contribution from the 1 day interferogram in order to construct a velocity map, but, because of its relatively short baseline perpendicular to the radar line of sight $\left(B_{n}\right)$ it cannot be used for detailed topographic analysis (Table 1). The sensitivity of the interferometer to topography is proportional to $B_{\mathrm{n}}$ :

$$
\frac{\phi_{\mathrm{t}}}{z} \approx-\frac{2 k B_{\mathrm{n}}}{\sin \theta R_{0}}
$$

where $\phi_{\mathrm{t}}$ is the phase contribution due to topography, $z$ is the elevation, $\theta$ is the radar incidence angle, $k$ is the wavenumber ( $2 \pi /$ wavelength) and $R_{0}$ is the slant-range distance (Joughin and others, $1996 \mathrm{~b}$, equation (9)). Each phase cycle $(-\pi$ to $+\pi$ ) of the double-difference interferogram represents about $370 \mathrm{~m}$ of elevation, which translates to about three phase cycles over the approximate elevation range of the icefield in this area $(1200 \mathrm{~m})$. In contrast, typical ERS-1 interferometers used to generate DEMs (Zebker and others, 1994; Joughin and others, 1996b) yield an elevation-to-fringe ratio which is $2-8$ times more sensitive to topography. The ratio of Equation (2) can also be used to estimate the error in the interferometric topography $\left(\sigma_{\mathrm{z}}\right)$ introduced by phase noise $\left(\sigma_{\phi}\right)$. Phase noise is calculated from the coherence $(\gamma)$ :

$$
\sigma_{\phi}=\frac{1}{\sqrt{N}} \frac{\sqrt{1-\gamma}}{\gamma}
$$

where $N$ is the number of looks of the interferogram ( $N=0$ ) (Rodriguez and Martin, 1992). Phase noise in the double-difference interferogram over the areas of typical coherence (0.6) and areas of low coherence $(0.4)$ yields $\sigma_{z}$ of 18 and $36 \mathrm{~m}$, respectively. Errors of this magnitude prevent the DEM from being used for detailed topographic analysis or as a benchmark to estimate future glacier elevation changes. Additional errors from baseline uncertainties, atmospheric delays and receiver clock noise are more difficult to quantify (Rignot and others, 1996a). Local errors may also result from differences in the penetration depth of the $L$-band 
signal into the snow/firn and ice, as well as multiple scattering from very rough surfaces such as crevasses, which lengthens the phase path length.

Since there are no topographic maps available for this area, a filtered version ( 25 pixel median filter) of the DEM is still useful and is shown in Figure 4 draped over an amplitude SAR image. The DEM covers only the icefield and excludes the nunataks and some areas on the ice where coherence values are low or unwrapping errors occurred. The elevations range from $800 \mathrm{~m}$ (dark blue), near the area where phase coherence is lost on Glaciar Europa, up to
$2200 \mathrm{~m}$ (dark red). The approximate locations of the two primary topographic divides on the icefield between Glaciares Europa and Penguin are indicated as black lines (Fig. 4) and are used in the analysis of the ice divides in the next section.

\section{Ice motion}

The very short baselines which introduce large errors into the DEM are advantageous for surface displacement measurements. The $28 \mathrm{~m}$ perpendicular baseline of the 1 day in-

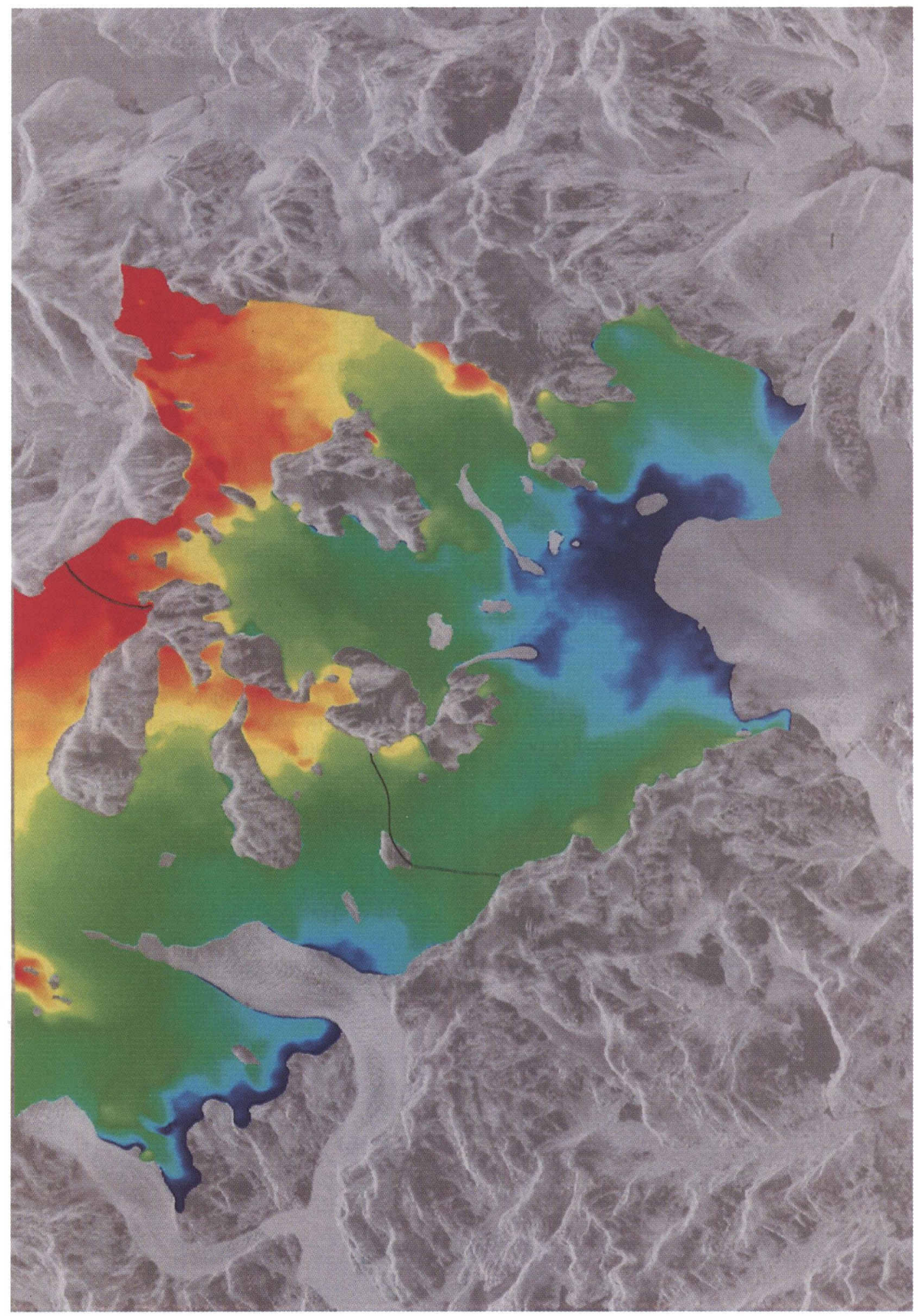

Fig. 4. A median-filtered DEM of the icefield generated from the double-difference interferogram over an amplitude image. Dark blue is $800 \mathrm{~m}$ and dark red is $2200 \mathrm{~m}$. The two black lines on the DEM are the topographic divides between Glaciares Europa and Penguin. 
terferometer (Table 1) yields a sensitivity of $570 \mathrm{~m}$ of elevation per phase cycle (Equation (2)) which translates into two cycles of phase for the range of icefield elevations. In contrast, one phase cycle represents $0.12 \mathrm{~m}$ of displacement (Equation (1)), implying the lday interferometer is over 4000 times more sensitive to displacement than to topography. Since the phase of the unwrapped-flattened lday interferogram is dominated by displacement contributions, only a general DEM is needed to remove the broad-scale. topographic phase. The phase-noise-induced errors in the DEM $(18-36 \mathrm{~m})$ result in velocity errors of $0.6-1.2 \mathrm{~cm} \mathrm{~d}^{-1}$ (Joughin and others, 1996b, cquation (15)). The errors of the velocity measurements $\left(\sigma_{\mathrm{v}}\right)$ due to phase noise $\left(\sigma_{\phi}\right)$ in the 1 day interferogram are related to coherence (Equation (3)):

$$
\sigma_{\mathrm{v}}=\frac{\lambda}{4 \pi} \sigma_{\phi}
$$

The phase-noise-induced velocity errors (and their corresponding coherences) are $4.6 \mathrm{~mm} \mathrm{~d}^{1}(0.72)$ for typical areas of the icefield, $7.3 \mathrm{~mm} \mathrm{~d}^{-1}(0.57)$ within the shear zones and $14.1 \mathrm{~mm} \mathrm{~d}^{-1}(0.36)$ at the lower part of Glaciar Europa affected by melting.

The additional errors from baseline uncertainties, atmospheric delays and receiver clock noise also apply to the 1 day interferogram and therefore directly to the velocity measurements. The cumulative effect of these errors is small and can be measured as the velocity of small ice-free regions which are assumed to have zero displacements. Most of the ice-free areas were manually masked because of their very low coherence $(<0.2)$. The rock areas remaining are labeled in Figure 5. The perimeter of all rock areas has apparent velocities of $0 \pm 1.0 \mathrm{~cm} \mathrm{~d}^{-1}$. This velocity range is shown as black in Figure 6. (There are non-rock areas with this velocity range, and their origin is explored in the next sec-

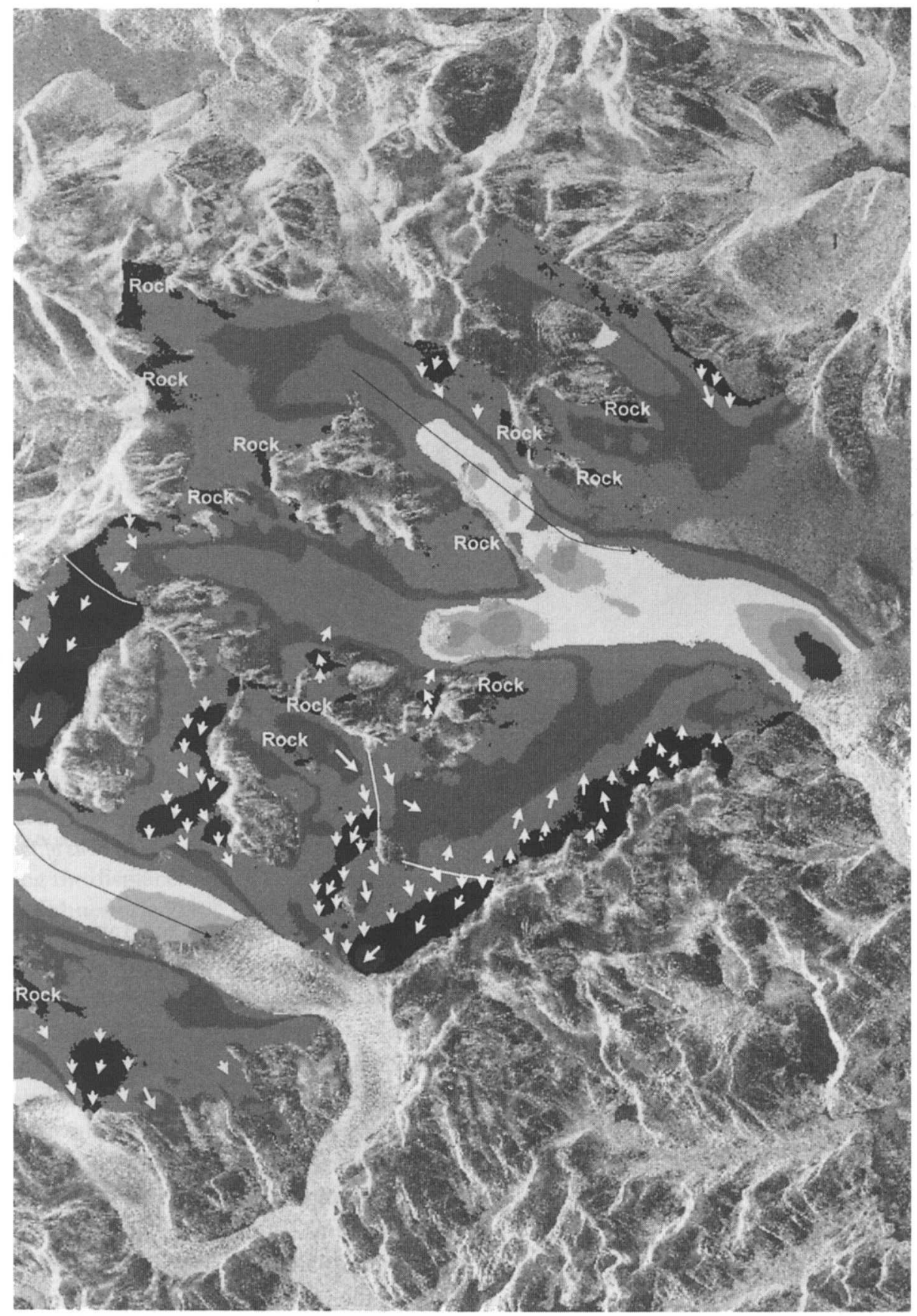

Fig. 5. Model of the flow patterns (white arrows) near the areas of transition from flow toward (dark shades) to flow away from (light shades) the radar illumination direction. The length of the arrows is not proportional to speed.Velocity contours are a gray-scale representation of Figure 6 . 


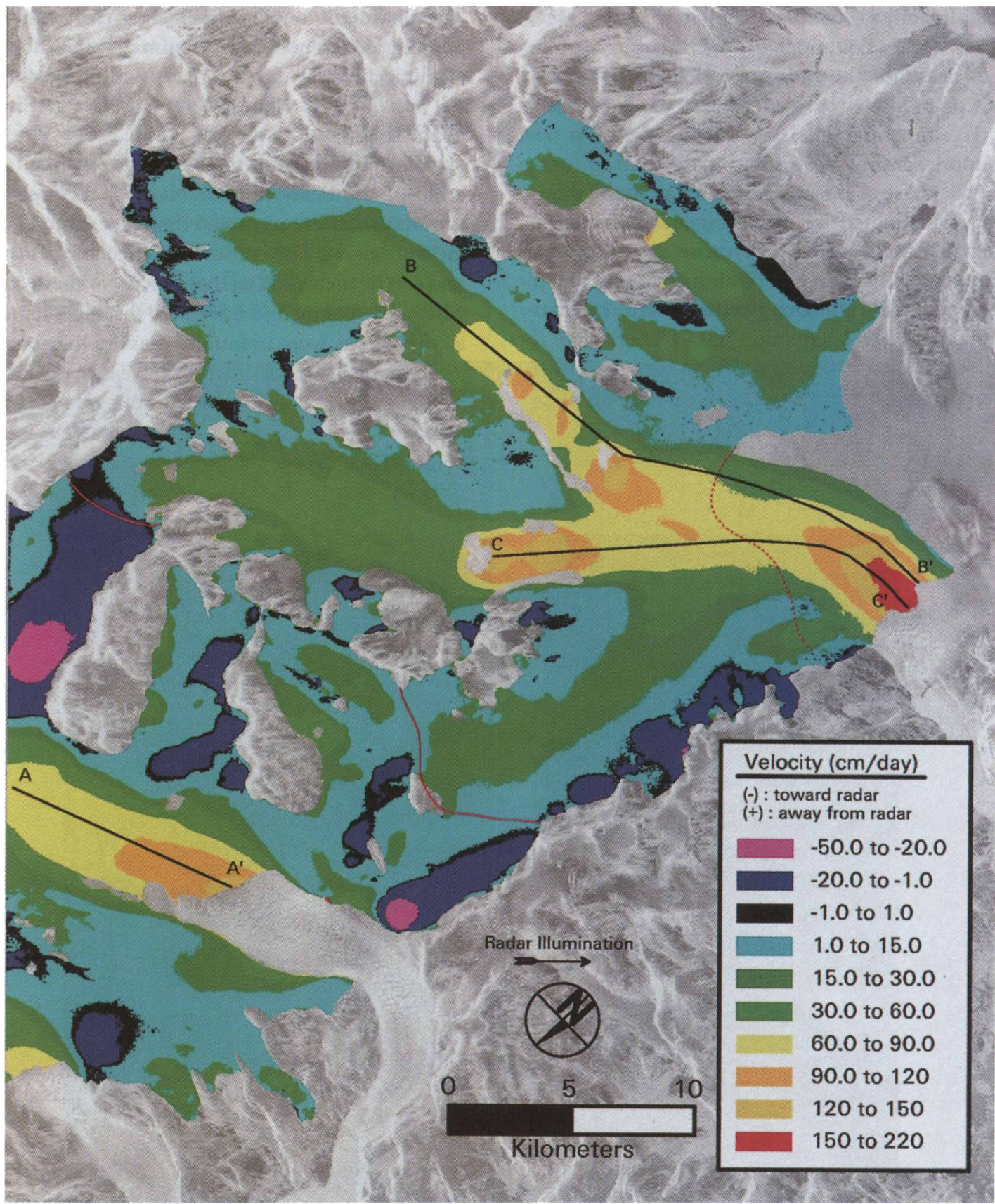

Fig. 6. Map of the ice velocity in the radar line of sight (from left). The solid red lines are the topographic divides from the DEM (Fig. 4). The dashed red line is the boundary between the velocity map with topographic phase removed (left) and the velocity map derived directly from the flattened-unwrapped 1 day interferogram (right). The black lines are the locations of the velocity profiles shown in Figures 7-9.

tion.) The locations of the rock areas span nearly the full extent of range and azimuth, implying any residual tilt in the interferogram from errors in estimating the baseline produces velocity errors less than $\pm 1.0 \mathrm{~cm} \mathrm{~d}^{-1}$. The interior area of a few of the rock outcrops has a measured velocity of $-2 \mathrm{~cm} \mathrm{~d}^{-1}$. This error is greater than the $1.41 \mathrm{~cm} \mathrm{~d}^{-1}$ phase error calculated for the low-coherence areas, and therefore we can estimate the combined effect of the baseline uncertainties, atmospheric delays and receiver clock noise errors as $\approx 2 \mathrm{~cm} \mathrm{~d}^{-1}$. This value serves as an upper bound because it is impossible to determine from the amplitude image if some of the areas labeled bare rock contain the edges of small cirque glaciers with true ice motion.

The ice-velocity map (Fig. 6) is spatially limited by the extent of the DEM. The phase of the 1 day interferogram was successfully unwrapped on a larger part of the lower end of Glaciar Europa. In this area the double-difference phase contained many unwrapping errors, and the assumption of steady ice flow over the longer time period is probably not appropriate approaching the terminus. Therefore, no $\mathrm{DEM}$ was generated for this area. The 1 day interferogram is dominated by displacement, and the change in elevation across lower Europa is estimated to be $<200 \mathrm{~m}$ based on control points near the limit of the DEM and the ice front. Therefore, the assumption that the phase is independent of topography results in a relative velocity error of $4.2 \mathrm{~cm} \mathrm{~d}^{-1}$ (Equations (1) and (2)). This relative velocity field was converted to absolute velocity by adding a phase constant forcing the velocity to be continuous across the boundary (Fig. 6, red dashed line) with the DEM-derived velocity map. Similar extensions could not be added to the Penguin and HPS-19 glaciers because the limits of successful unwrapping for the 1 day and double-difference interferograms coincided. 


\section{ANALYSIS OF ICE VELOCITY}

\section{Radar line-of-sight velocities}

The ice-velocity map contains only the component of ice motion in the direction of the radar illumination, but reveals the great spatial variation in velocity within this geometrically complex part of HPS (Fig. 6). The two purple hues represent ice motion toward the radar. The range of colors from blue (low velocity) to red (high velocity) represent motion away from the radar. The narrow range of velocities near zero, which includes the transition from ice motion away from to ice motion toward the radar, is shown in black. Whilc much of the complexity of the map, particularly the change in sign of the velocity, can be attributed to the change in flow direction relative to the radar illumination direction, there are several obvious characteristics of the velocity field worth noting. The velocity patterns of the lower parts of all three glaciers are indicative of a central core of fast-flowing ice bordered by the slower-moving icefield on either side. The same observation was made by SIR-C InSAR for Glaciar San Rafael, Chile (Rignot and othcrs, 1996a), and for Columbia Glacier, Alaska, from photogrammetry techniques (Meier and others, 1985). The ice accelerates toward the glacier tcrmini and reaches a maximum linc-of-sight velocity of $0.9,1.5$ and $2.2 \mathrm{~m} \mathrm{~d}^{-1}$ for the HPS-19, Penguin and Europa glaciers before phase coherence is lost. (These velocities represent the motion in the direction of the radar illumination, from the left of Figure 6 inclined $57^{\circ}$ from the horizontal, and therefore underestimate the ice-surface velocity, which is computed along transects in the following subsection.) There are scvcral circular regions of high velocity separated by troughs of slower velocity on the two upper tributaries of Glaciar Europa.

\section{Velocity profiles}

In order to construct a complete two-dimensional map of ice velocity, at least one more interferogram with an opposing line of sight is required (Goldstein and others, 1993; K wok and Fahnestock, 1996). For areas where the flow direction $(\zeta)$ and surface slope $(\phi)$ is known, the radar line-ofsight velocity $\left(v_{\mathrm{r}}\right)$ can be projected onto the ice surface in the direction of flow yiclding an ice-velocity measurcment

$$
v_{\mathrm{s}}=\frac{v_{\mathrm{r}}}{\cos \phi \cos \zeta \sin \theta-\sin \phi \cos \theta},
$$

cquivalent to measuring the displacement of a feature on the ice surface (K wok and Fahnestock, 1996). The assumption of ice motion parallel to the ice surface is valid since the vertical component due to ablation is very small compared with the motion over most of the glacier. The horizontal component of the ice-surfacc velocity in the flow direction $\left(v_{\mathrm{f}-\mathrm{h}}\right)$ is calculated along the path of three flowlines that are observed on the amplitude image (Fig. 2). The location of the transects is also shown on the ice-velocity map (Fig. 6). The surface slope along the transects is calculated from the median-filtered DEM. The velocity profiles are smoothed using a boxcar-averaging function with a width of 50 pixels $(\approx 750 \mathrm{~m})$. Longitudinal strain rate is computed as $\Delta v_{\mathrm{fl}-h} / \Delta d_{\mathrm{fl}}$, where $d_{\mathrm{fl}}$ is the distance between velocity measurements along the transect $(\approx 15 \mathrm{~m})$.

\section{Transect $A$}

The ice velocity along the center line of Glaciar Penguin gradually increases from 1.7 to $2.0 \mathrm{~m} \mathrm{~d}^{1}$ during the first $3.5 \mathrm{~km}$ of the transect before quickly rising to $2.6 \mathrm{~m} \mathrm{~d}^{3}$ in the last $1.5 \mathrm{~km}$ (Fig. 7a). While the data end approximately $14 \mathrm{~km}$ from the terminus, this trend is similar to velocities recorded approaching the termini of other tidewater glaciers (Meier and others, 1985; Naruse and others, 1995; Rignot and others, 1996a) which can be attributcd to a dominance of basal sliding and the diminution of longitudinal back-stress on the terminus (Mcier and Post, 1987). At this distance from the terminus the sharp increase in velocity is more likely the result of an increase in basal sliding, possibly due to an influx of subglacial water from increasing melt at lower elevations along with the availability of crevasse drainage.

Longitudinal strain rates in the first $3.5 \mathrm{~km}$ are slightly higher than the $10^{-2} \mathrm{a}^{-1}$ typical of temperate glaciers (Paterson, 1994) (Fig. 7b). The small oscillations from compressive to extensional flow may be a reflection of bedrock bumps. The strain rate at the location where crevassing begins along the transect is $0.25 \mathrm{a}^{-1}$ and indicated by the vertical line in Figure $7 \mathrm{~b}$.

The location of crevasse initiation from the amplitude image (Fig. 2) combined with strain rates measured along the center line (Fig. $7 \mathrm{~b}$ ) allow the tensile strength of the ice to be estimated. Vaughan (1993) used published strain-rate measurements from field observations and remote-sensing data of crevassed and uncrevassed locations to estimate temperate- and polar-ice tensile strength. His model assumes crevassing is controlled by the strain rate in the deep ice and hence its constitutive relationship. The firn acts as a thin surface layer contributing little to the strength of the ice mass. The range of tensile strength found from the four temperate glacier studies cited is $90-200 \mathrm{kPa}$, all values being based on field obscrvations.

The relationship used for converting strain rates to devia-
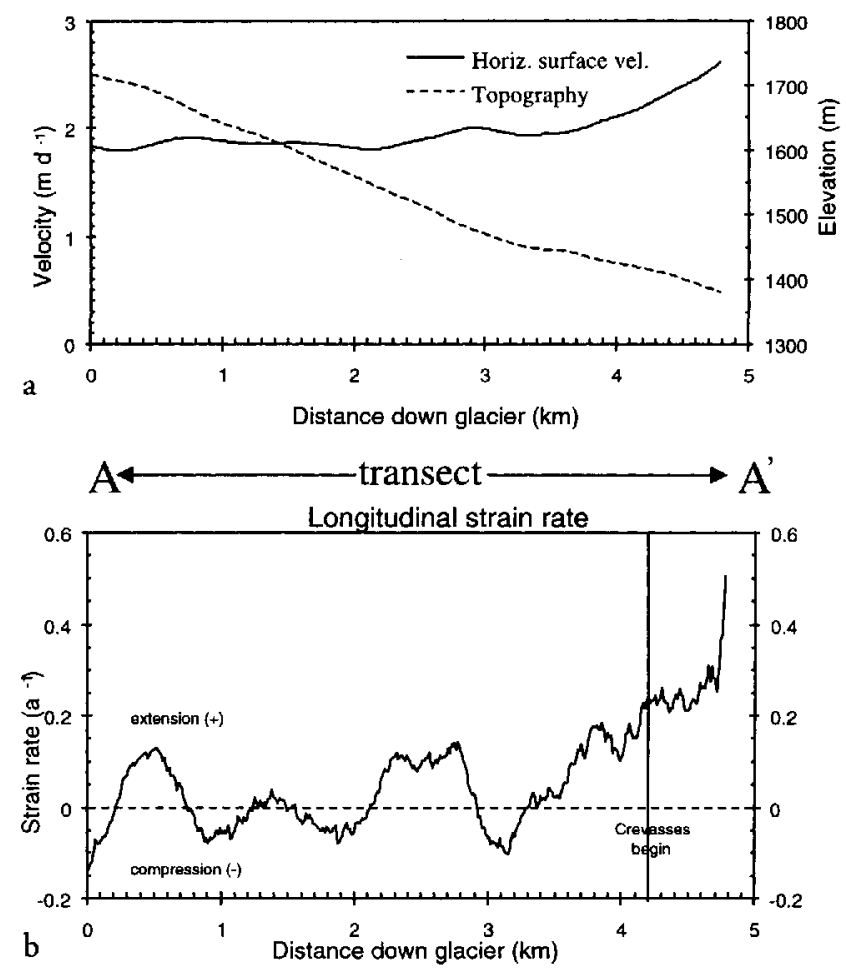

Fig. 7. Glaciar Penguin flowline transects of (a) horizontal ice velocity and lopography from the median-filtered DEM and (b) longitudinal strain rate: compression ( - ) and extension $(+)$. The location of the initiation of crevassing as determined from the amplitude image ( Fig. 2) is shown in ( $b$ ). The location of the transect is shown in Figures 5 and 6. 
toric stress simplifics to Glen's flow law of ice under the assumption of only one surface component of strain, as is typically assumed along the center line. The symmetry of the crevasscs about the center line (Fig. 2) supports the assumption of minimal lateral strain and therefore the use of the flow law. However, ice fractures in response to the absolute stress and not the deviatoric stress. The relationship between the longitudinal deviatoric stress $\left(\sigma_{L}^{\prime}\right)$ and the tensile strength of ice $\left(\sigma_{\mathrm{T}}\right)$ is dependent on the failure criteria. Using the maximum octahedral shear-stress (von Mises) criterion (Ramsay, 1967) with the assumption of no lateral strain, we find

$$
\sigma_{\mathrm{T}}=\sqrt{3} \sigma_{\mathrm{L}}^{\prime}
$$

Applying Griffith's criterion (Jaeger and Cook, 1979) predicts

$$
\sigma_{\mathrm{T}}=2 \sigma_{\mathrm{L}}^{\prime}
$$

The tensile strength of ice can now be estimated from our observations of strain rate by incorporating the flow law with Equations (6) and (7), respectively:

$$
\begin{aligned}
& \text { Mises criterion } \sigma_{\mathrm{TM}}=\sqrt{3}\left(\frac{\dot{\epsilon}}{A}\right)^{\frac{1}{3}}, \\
& \text { Griffith's criterion } \sigma_{\mathrm{TG}}=2\left(\frac{\dot{\epsilon}}{A}\right)^{\frac{1}{3}},
\end{aligned}
$$

where $\dot{\epsilon}$ is the InSAR-derived longitudinal strain rate and $A$ is related to the steady-state creep and dependent on temperature, impuritics and crystal orientation of the ice.

The observed strain rate at crevasse initiation $\left(0.25 \mathrm{a}^{-1}\right)$, with $A$ set to Paterson's $(1994$, p. 97) recommended value for temperate ice $\left(6.8 \times 10^{-15} \mathrm{~s}^{-1} \mathrm{kPa}^{-3}\right)$, implies the tensile strength of the ice is $182 \pm 5$ and $210 \pm 5 \mathrm{kPa}$ from Equations (8) and (9), respectively. (The error estimate is based on the $2 \mathrm{~cm} \mathrm{~d}^{-1}$ uncertainty in the ice velocity and the effect of the smoothing function on the profiles.) This result, using $15 \mathrm{~m}$ pixels to locate the crevassing, is within the range of tensile strengths measured during the field-based studies mentioned above. This also supports Vaughan's (1993) conclusion that derived tensile strength is not significantly influenced by the resolution of the data.

\section{Transect $B$}

The velocity profile of the south branch of Glaciar Europa follows a flowline that can be traced almost continuously from the amplitude image. Within the first $9 \mathrm{~km}$ of the transect the velocities fluctuate dramatically over short distances, reaching a maximum of $2.6 \mathrm{~m} \mathrm{~d}^{-1}$ near $5 \mathrm{~km}$, then slowing to a near constant speed of $0.4 \mathrm{~m} \mathrm{~d}^{-1}$ before accelerating to $3.3 \mathrm{~m} \mathrm{~d}^{-1}$ at the cnd of the transect (Fig. 8a). The magnitude and fluctuation of these velocities are very similar to those found on Columbia Glacier (Meier and others, 1985, fig. 13). Beyond $10.5 \mathrm{~km}$, where there is no InSAR DEM because of low coherence in the double-difference interferogram, the surface velocities are derived directly from the flattened unwrapped phase of the 1 day interferogram. The topography in this area is estimated by assuming a constant slope to a control-point elevation near the end of the transect.

The longitudinal strain rate for this transect can provide insight into the flow dynamics. The peaks at 2.3 and $4.3 \mathrm{~km}$ coincide with locations where the valley walls narrow the width of the glacier. This causes transverse compression of the ice, which is compensated by longitudinal extension (Paterson, 1994). As the valley widens down-glacier, the flow tends to be more compressive. There are two points along the transect where crevassing initiates, with a crevasse-free
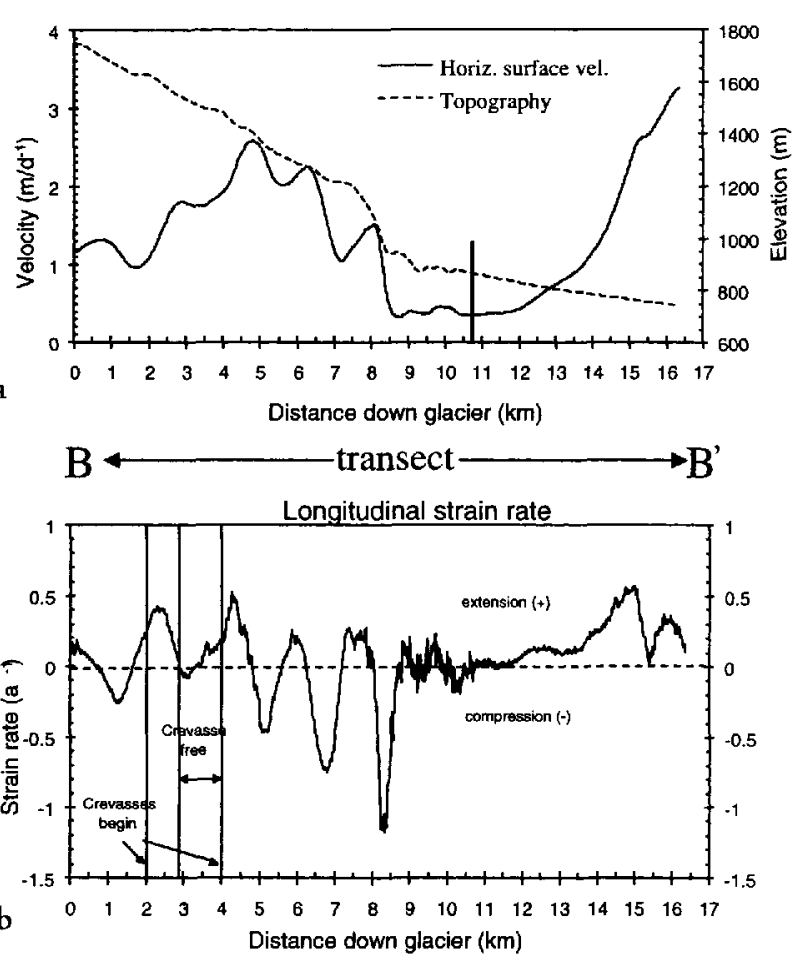

Fig. 8. Glaciar Europa south-tributary flowline transects of (a) horizontal ice velocity and topography from the medianfillered DEM and (b) longitudinal strain rate: compression $(-)$ and extension $(+)$. The location of the initiation of $\mathrm{cre}$ vassing as determined from the amplitude image (Fig. 2) is shown in (b). Velocity and topography to the right of the thick verical line in (a) are derived from the 1 day interferogram and extrapolated to a control point, respectively. The location of the transect is shown in Figures 5 and 6.

zone between them (Fig. $8 \mathrm{~b}$, vertical lines). At the point near $2 \mathrm{~km}$ the strain ratc is $0.3 \mathrm{a}^{-1}$, which translates to a tensile strength of $194 \pm 4$ and $224 \pm 5 \mathrm{kPa}$ from Equations (8) and (9), respectively. This is slightly higher than the tensile strength found on Glaciar Penguin and at the upper end of the range cited above (Vaughan, 1993). Crevassing continues down-glacicr until the $2.9 \mathrm{~km}$ location where a small compressive region begins and crevasses are no longer detected until the strain ratc climbs back to $0.2 \mathrm{a}^{-1}$ (tensile strength $169 \pm 6$ and $195 \pm 6 \mathrm{kPa}$ from Equations (8) and (9), respectively) at $4.1 \mathrm{~km}$. Below this point it is difficult to detect the presence or absencc of crevasses. The reinitiation of the crevassing at a lower strain rate, implying a lower tensile strength, seems reasonable since the ice was previously fractured. The very large compressive strain rate $\left(-1.1 \mathrm{a}^{-1}\right)$ at $8.3 \mathrm{~km}$ is associated with the end of a very steep section (Fig. 8a) corresponding to a bright area in the amplitude image (Fig. 2). This feature is most likely an icefall. The increased noise of the strain ratc between 9 and $11 \mathrm{~km}$ is a result of low phase coherence in the 1 day interferogram caused by the suspected melting episode discussed above. The strain rate begins to increase at $12 \mathrm{~km}$ as the glacier accelerates toward the terminus.

\section{Transect $C$}

The velocity profile of the north branch of Glaciar Europa begins below a gap in the velocity map and DEM which resulted from low coherence (Fig. 9a). This profile is similar to the last $11 \mathrm{~km}$ of the south-branch velocity profile (Fig. $8 a)$, with local velocity maxima corresponding to steepened 

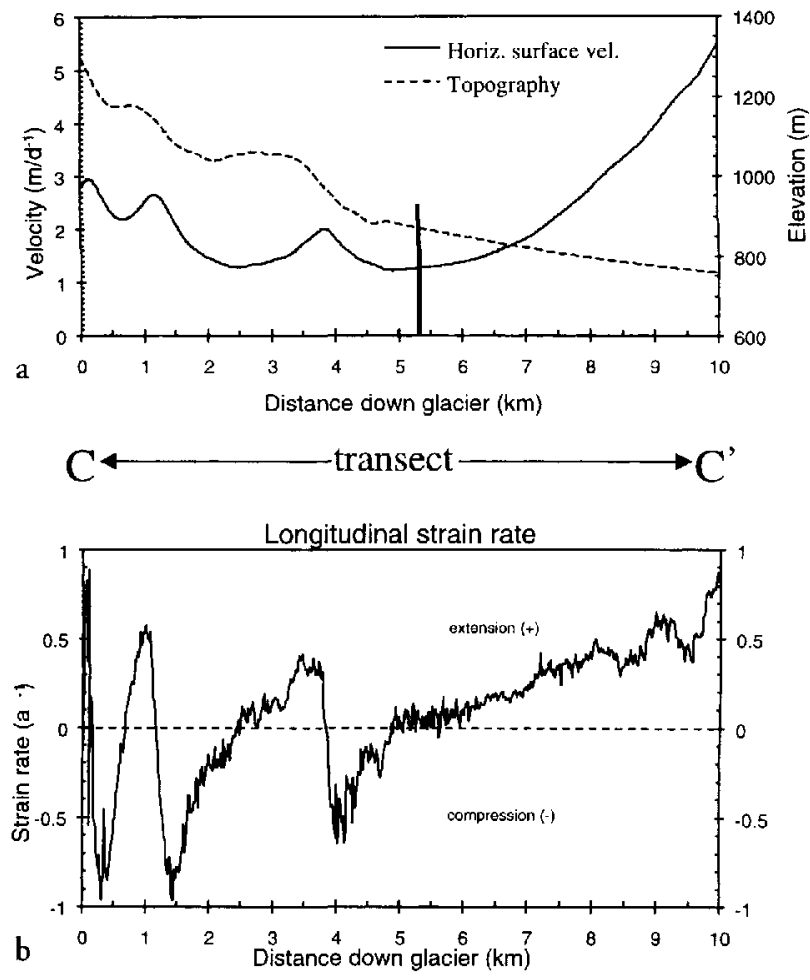

Fig. 9. Glaciar Europa Jlowline transects of (a) horizontal ice velocity and topography from the median-filtered DEM and (b) longitudinal strain rate: compression ( - ) and extension $(+)$. Velocity and topography to the right of the thick vertical line in (a) are derived from the 1 dav interferogram and exirapolaled to a control point, respectively. The location of the transect is shown in Figures 5 and 6.

topography followed by an acceleration toward the terminus. The flowline from the north tributary ends in the area of maximum velocity, reaching $5.4 \mathrm{~m} \mathrm{~d}^{-1}$. The longitudinal strain rate (Fig.9b) is also similar to that of the last $11 \mathrm{~km}$ of the south branch (Fig. 8b). Since the transect begins below the initial crevassing location, strain rates from this profile cannot be uscd to compute tensile strength.

\section{Flow divides}

Since a flow divide is defined as a location where the horizontal component of the ice velocity is zcro (Paterson, 1994), one might expect flow divides to be identifiable on an InSAR velocity map. Flow divides and thcir analogous feature on ice caps, flow centers, are found near topographic divides and summits but do not always have coincident locations. A flow divide can be displaced from a topographic divide because of asymmetric bedrock slopes (Paterson, 1994) or a gradicnt of net accumulation across the divide (Van der Veen and Whillans, 1992).

Flow divides and flow centers are important glaciological featurcs that are difficult to locate, requiring intensive field measurements. Ice cores for paleoclimatic interpretation are desirablc from ice-flow centers where corruption of the time depth relationship from horizontal motion is minimized (Van der Veen and Whillans, 1992). In order to measure the total mass balance of a glacier, its surface area must be known. In areas where individual glaciers originate from a common accumulation zonc the flow divides must be mapped. The location of flow divides on HPS are additionally significant as they form part of the disrupted boundary betwecn Chile and $\Lambda$ rgentina.
The numerous largc nunataks and the generally ice-free continental divide in the southern part of HPS segregate the outlet glaciers into individual mountain glaciers separated by small flow divides. In this scene there are two segments of the flow divide which cross the icefield, separating ice. flowing between Glaciares Europa and Penguin. The topographic divides on the icefield, estimated from the DEM, are shown in Figure 5 as red lincs.

There is an area of zero velocity near the upper topographic divide between Glaciares Europa and Penguin which may represent the flow divide. Other zero-velocity bands are the result of ice flow perpendicular to the radar line of sight, but no rcasonable model of flow patterns can cxplain the band of zero velocity near the upper topographic divide (Fig. 6). Therefore, we believe this band of near-zcro velocity represents the upper flow divide between Glaciares Europa and Penguin.

There is no similar band of zero velocities near the lower topographic divide between Glaciares Europa and Penguin. The velocity along the topographic divide is at a local minimum and averages about $6 \mathrm{~cm} \mathrm{~d}^{-1}$. This is outside the expected cumulative crror for velocity measurements and must be explained by something other than systematic errors. The elevation of the two divides may explain the difference. The upper divide is near the highest point on the icefield at $2100 \mathrm{~m}$. The lower divide is separated by a rock outcrop with the lower part straddling a gently sloping plateau at $1400 \mathrm{~m}$. The upper part of the lower divide runs across an ice ridge at $1550 \mathrm{~m}$. At thesc lower elevations it is conceivable that daily ablation rates approach several $\mathrm{cm} \mathrm{d}^{-1}$. This vertical contribution to the radar line-of-sight velocity could be masking the zcro horizontal velocity. Another possible explanation for the lack of zero velocities at the lower divide is a non-stcady-statc condition where one of the glacier's drainage areas encroaches on the other.

\section{Flow patterns}

Thus far two situations have been identified that produce near-zero ice velocity, stationary icc-frec arcas and ice at a flow divide. The remaining bands of near-zero ice velocity distinguish areas of ice motion toward the radar from areas of ice motion away from the radar. These areas are thought to be locations where the velocity vector is perpendicular to the line of sight and therefore no motion is detected by the interferometer. The location of these low-velocity bands in areas where no flowlincs are visible is used to constrain the orientation of the velocity vector in that area. $\Lambda$ model of the general ice-surface flow direction is made from the locations of perpendicular flow superimposed on the lineof-sight velocity map (Fig. 6).

\section{SUMMARY AND GONCLUSIONS}

The L-band InSAR data of the Europa and Penguin glacier section of HPS allow us to demonstrate new glaciological applications of InSAR data and provide the first quantitative glaciological information for this area. In addition, the limitations of the technique for parts of the glaciers provide guidance for the acquisition schedule of futurc InSAR missions for temperate glaciers.

The application of InSAR to flow-divide mapping demonstrated that ice-flow divides may be located from a line-of-sight velocity map, but their detection may be lim- 
itcd in arcas of high daily ablation. $A$ n additional $\operatorname{InS} \Lambda \mathrm{R}$ velocity map with a different line of sight would allow extensive flow-divide mapping for a selection of ice-core sites, and drainage mapping of icefields and ice sheets. InSAR velocity along a glacier center line, where only longitudinal strain is present, and the accompanying amplitude image for crevasse detection permit the tensile strength of ice to be estimated from a combination of InSAR data and the flow law of glacier ice. Coincident data of strain rates and crevasse initiation are nccded to test physically based models of crevasse formation which are essential to the understanding of glacier calving processes (Van der Veen, 1997). InSAR observations along a center line can readily supply these data. The flow direction of parts of the glacier where no flowlines are present can be constrained from the line-of-sight velocity map in areas where the ice-flow direction passes through the orientation perpendicular to the radar line of sight. Thus, with even a single component of velocity the vector orientations in some featureless areas can be constraincd.

The limitation of temporal baselines for L-band InSAR techniques on temperate glaciers is illustrated by the coherence maps of this area. Two different phenomena are shown to cause isolated areas of low coherence on the glaciers, which limit the spatial extent of the InSAR data. The first is due to high glacial velocity and directly related to the length of time between the InSAR acquisitions. I arge, uniform displacements within $5-15 \mathrm{~km}$ of the terminus, and large, differential displacements within the shear margins cause loss of interferometric data. Near the terminus an alternative application of the repeat-orbit amplitude data is more cffective Rott and others, 1998; Michcl and Rignot, in press). The second process that results in low coherence is melting. It changes the physical properties of the snow/ firn, thereby altering the scattering propertics of the glacier. Thus, even though L-band's longer wavelength makes it superior to C-band for InSAR studies on temperate glaciers, there are considerable limits to the temporal baseline for fast-flowing glaciers, cspccially in the presence of freezc/ thaw conditions. This implies that winter acquisitions of InSAR data are desirable.

From a map of only the radar line-of-sight vclocity it can be seen that the Europa, Penguin and HPS-19 outlet glaciers have central cores of high-velocity ice flanked by slower-moving ice. Knowledge of the flow direction greatly enhances the utility of the radar line-of-sight ice-velocity map for glaciological interpretation. The horizontal component of the ice velocity computed along a flowline of Glaciar Furopa reaches a maximum of $5.5 \mathrm{md}^{-1}$ and varies rapidly, with several local maxima and minima occurring within both the north and south tributaries. Consequently, there arc areas of high longitudinal strain rate $(>0.5 \mathrm{a})$ which are attributed to a narrowing of the glacier. The horizontal velocity profile along the center line of Glaciar Penguin is typical of a tidewater glacier approaching the terminus. The center-line longitudinal strain rates at the locations of crevasse initiation for both glaciers imply tensile strengths of icc $(169-224 \mathrm{kPa})$ which are within the range of field-based measurements on temperate glaciers.

\section{ACKNOWLEDGEMENTS}

Support for this work was provided by NASA through SIR-
C grant 958745. The strain-rate analysis was done while R. F. was a Byrd Post-doctoral Fellow at the Byrd Polar Research Center. The authors are thankful for the insightful comments of $\mathrm{G}$. Casassa and $\Lambda$. Rivera on an early manuscript and for their inspiration during a December 1995 visit to the Patagonian iceficlds by R.F. and E.R. The authors are grateful for the perceptive suggestions of the reviewers $C$. Warren and A. Luckman. 'I his is Byrd Polar Rescarch Genter contribution No. 1138.

\section{REFERENCES}

Aniya, M., R. Naruse, M. Shizukuishi, P. Skvarca and G. Casassa. 1992 Monitoring recent glacier variations in the Southern Patagonia Ircficld, utilizing remote sensing data. Int. Arch. Photogramm. Remole Sensing 29 (B 7$), 87-94$.

Aniya, M., H. Sato, R. Narusc, P. Skvarca and G. Casassa. 1996. The use of satellite and airborne imagery to inventory out let glaciers of the Southern Patagonia icefield, South America. Photogramm. Eng. Remote Sensing, 62(12), $1361-1369$.

Escobar, F., F. Vidal, C. Garin and R. Naruse. 1992. Water balance in the Patagonia Icelield. In Naruse, R. and M. Aniya, eds. Glacidogical resuarches in Patagonia, 1990. Nagoya, Japanese Society of Snow and Ice. Data Center for Glacier Research, 109-119.

Fatland, D. R. and C.S. Iingle. 1996. Pre- and post-surge measurements of Bering Glacier using SAR interferometry. [Abstract.] EOS, 77/46], Fall Meeting Supplement, F194.

Goldstcin, R. M., H. A. Zcbker and C. I. Werner. 1988. Satcllite radar interferometry: two-dimensional phase unwrapping. Radio $S_{c i,}, 23(4), 713720$

Goldstein, R. M., H. Engelhardt, B. Kamb and R. M. Frolich. 1993. Satellite radar interferometry for monitoring icc sheet motion: application to an Antarctic ice strcam. Stience, 262(5139), 152.5-1530.

Jacger, J. C. and N. G.W. Cook. 1979. Fundamentals of rock mechanics. Third ediion. London, Chapman and Hall.

Joughin, I. R., D. P. Wincbrenner and M. A. Fahnestock. 1995. Observations of ice-sheet motion in Grenland using satellite radar interferomctry. Geophys. Res. Letl., 22(5), 571574.

Joushin. I., R. Kwok and M. Fahnestock. 1996a. Estimation of ice-sheet motion using satellite radar interferometry: method and crror analysis with application to Humboldt Glacier, Greenland. F. Glaciol, 42(142), 564-575.

Joughin, I., D. Winebrenner, M. Fahnestock, R. Kwok and W. Krabill. 1996b. Measurement of icc-shcet topography using satellite-radar interferometry. 7. Glariol., 42(140), 10-22

Joughin, I., S. 'Tulacryk, M. Fahnestock and R. Kwok. 1996c. A mini-surge on the Ryder Glacier, Greenland, observed by satellite radar interferometry. Science, 274 $5285 ; 228-230$.

Kwok, R. and M. A. Fahnestock. 1996. Ice shect motion and topography from radar interforometry. IFEE Trans. Geosti. Remule Sensing, GE-34 11, 189-200.

Kwok, R. I. R. Joughin and K. Jezek, 1996. Antarctic ice shelf flow regimes from radar interferometry. [Abstract.] EOS, 7746). Fall Mecting Supplement, F195.

MacAyeal, D. R. and E. Rignot. 1996. Does Hemmen Ice Rise stabilize the calving front of the Ronne Ice Shelf? [Abstract.] EOS, 77,46;, Fall Meeting Supplement, F195.

Mätsler, C. 1987. Applications of the interaction of microwaves with the natural snow cover. Remole Sensing Rez., 2,2, 259387.

Meier, M. F. and A. Post. 1987. Fast tidewater glacicrs. 7. Geophys. Res. 92(B9), $9051-9058$.

Mrier, M.F., I. A. Rasmusser, R. M. Krimmel, R. W. Olsen and 1). Frank. 1985. Photogrammctric determination of surface altitude, tcrminus position, and ice velocity of Columbia Glacier, Alaska. C.S. Ceol. Sur. Prof. Pap. $1258-\mathrm{F}$

Michel, R. and E. Rignot. 1999. Flow of Glaciar Morcno, Argentina, from repeat-pass Shuttle Imaging Radar images: comparison of the phase correlation method with radar interferomel ry. F. Glariol., 45(149), 93-100.

Naruse, R., P. Skvarca, K. Satow, Y. Takeuchi and K. Nishida. 1995. Thickness change and short-term flow variation of Moreno Glacier, Patagonia. Bull. Glacier Res. 13, 21-28.

Nishida, K., K. Satow; M. Aniya, G. Casassa and T. Kadota. 1995. Thickness change and flow of Tyndall Glacier, Patagonia. Bull. Glacier Res, 13,29 34

Paterson. W. S. B. 1994. The physics of glaciers. Third dition. Oxford, etc, Elsevier Ramsay, J. G. 1967. The foiding and fracturing of meks. New York, McGraw-Hill.

Rignot, F. 1996. 'lidal motion, ice velocily and melt rate of Pctermann Gletscher, Greenland, measured from radar interferometry: 7. Glaciol. $42(142), 476-485$.

Rignot, E., K. C. Jezek and H. G. Sohn. 1995. Ice flow dynamies of the 
Greenland ice sheet from SAR interferometry Geoplys. Res. Lett, 225 . $575-578$.

Rignot. E., R. Forster and B. Isacks. 1996a. Interferometric radar observations of Claciar San Rafacl, Chile. 7. Glaciol., 42(141), 279-291; Erratum $\$ 2112), 591$.

Rignot, E., R. Furster and B. Isacks. 1996b. Mapping of glacial motion and surface topography of Hielo Patagónico Norte, Chile, using satellite S.IR L-band interferometry data. Ann. Glaciol., 23, $209-216$.

Rignot, F.J., S. P. Gogineni, W. B. Krabill and S. Ekholm. 1997. North and northeast Greenland ice discharge from satellite radar interferometry. Situce, $2765314 ; .934937$.

Rivera, A. H. I ange, J.C. Aravena and G. Casassa. 1997. The 20th-century advance of Glaciar Pio XI. Chilean Patagonia. Ann. Glaciol, 24, 66-71.

Rodriguez, E, and J. M. Martin. 1992. Theory and design of interferometric synthetic aperture radars. IEE Proc., Ser. F, 139(2), 147-159.

Rott. H., M. Stueler, A. Siegel, P. Skvarca and A. Eckstaller. 1998. Mass fluxes and dynamics of Moreno Glacier, Southern Patagonia Icefield. Geophs. Res. Lell. 25 9, 1.107-1410

Skvarca, P. and R. Narusc. 1997. Dynamic behavior of Glariar Perito Noreno. southern Patagonia. Am. Giacial, 24, 268271.

Skvarca. P., K. Satow, R. Naruse and J. C. Leiva. 1995. Recent thinning, retreat and flow of Lpsala Glacier. Patagonia. Bull. Glacier Res. 13, 11-20.

Skvarsa, P. M. Stucfer and H. Rott. In press. Temporal changes of Glaciar Mavo and Iatguna Escondida, southern Patagonia, detected by remote sensing data. Global and Panetary Change.
Takeuchi, Y., R. Naruse and P. Skvarca. 1996. Annual air-temperature measurement and ablation estimate at Moreno Glacier, Patagonia. Bull. Glacier Res. 11, 23-28.

Vachon, P.W., D. Geudtner, K. Mattar, A. I. Gray, M. Brugman and I. Cumming. 1996. Differential SAR interferometry measurements of Athabasca and Saskatchewan Glacier. Can. F. Remote Sensing, 22 (3), $287-296$.

Van der Vecn, C. J., ed. 1997. Calving glaciers: report of a Workshop, February 28 March 2, 1997. Byrd Polar Res. Cent. Ret. 15

Van der Veen. C. J. and I. M. Whillans. 1992. Determination of a flow center on an icc cap. 7 . Glaciol., 38 130$), 412-416$.

Vaugham, D. G. 1993. Relating the occurrence of crevasses to surface strain rates. 7. Glaciol, $39132 ; 255-266$.

Warren, C. R. and D. E. Sugden. 1993. The Patagonian iccficlds: a glacio-

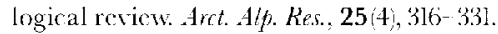

Warren, C. R., D. R. Greene and N. F. Glasser. 1995. Glaciar Lpsala, Patagonia: rapid calving retreat in fresh water. Ann. Glaciol. 21, 311-316.

Zebker, H. A. and R. M. Goldstein. 1986. Topographic mapping from interferometric synthetic aperture radar observations. 7. Geoftess. Res. 91 (B5), 49934999.

Zebker, II. A. and J. Villasenor. 1992. Decorrelation in interferometric radar chocs. IEEE Trans. Geosci. Remote Sensing, GE-30 (5), 950-959.

Zebker, H. A., C. L. Werner, P. A. Rosen and S. Hensley. 1994. Accuracy of topographic maps derived from ERS-1 interferometry. IEEE Trans. Geosci. Remote Sensing, GE-32 (4), 823-836.

MS received 27 Jamuary 1998 and accepted in revised form 16 December 1998 